\title{
CASE STUDY \\ ADVANCED INTEGRATED IN SITU TECHNOLOGIES OUTPERFORM TRADITIONAL REMEDIATION TECHNIQUES
}

\author{
KRISTIN FORSBERG
}

RGS 90 SVERIGE AB

\begin{abstract}
RGS 90 has been commissioned by the Swedish Armed Forces to remediate a large fuel storage facility servicing the military. The facility housed a variety of petroleum products for over 40 years and several documented release incidents resulted in the contamination of a $50,000 \mathrm{~m}^{2}$ area. The largest known event occurred in 1958, where an explosion caused the release of $14,000 \mathrm{~m}^{3}$ of various petroleum products. During the clean-up, only $8,000 \mathrm{~m}^{3}$ of the product was recovered while an estimated $6,000 \mathrm{~m}^{3}$ reached the surrounding environment. The client initially proposed a remedial strategy consisting of biosparging and in-situ chemical oxidation using hydrogen peroxide; however, RGS 90 found these methods to be unsuitable for this site due to the geology of the area, which consists of impermeable and heterogeneous dense, rocky moraine. There are also safety risks and environmental hazards associated with the use of hydrogen peroxide. RGS 90 suggested an alternative method which was accepted by the Swedish Armed Forces and a pilot test was carried out in 2012. The results from the pilot tests confirmed that the use of ORC-Advanced and RegenOx would successfully remediate the extensive TPH contamination at the site. The data gathered from this pilot test allowed RGS 90 to refine and optimize the proposed full-scale treatment of the wider plume. The full scale remediation process started in December 2013 in area C and D. Sampling 6 month after injection shows that the target values have been achieved in almost all sampling points. During summer and autumn 2014, RGS 90 are planning for the full scale remediation process of the remaining areas, (B1-B3). The plan is to inject RegenOx and ORC-Advanced into the ground and groundwater and use multiphase extraction in the areas, where free phase product has been observed during the initial groundwater sampling.
\end{abstract}

\section{KEYWORDS}

Soil remediation; in situ treatment; petroleum; injection; chemical oxidation; enhanced natural attenuation

\section{INTRODUCTION}

During the cold war, Sweden held secret fuel supplies in underground in readiness should war break out. These would then refuel jets using specially designed sections of road as make-shift runways.

One evening, in the summer of 1958, at one such fuel depot above a village called Moheda in the municipality of Alvesta, southern Sweden; the ventilation system in the storage bunker 


\section{Linnaeus ECO-TECH '14}

Kalmar, Sweden, November 24-26, 2014

lost power and switched off. In the rooms and spaces around the huge fuel tanks, dangerous levels of flammable vapours began to build up. When the site personnel returned to work in the morning, they restored the power, instantly causing an explosion to tear through the stores. Sadly, this resulted in loss of life. Also, the explosion ruptured some of the tanks, spilling fourteen million litres of fuel (45\% jet fuel, $42 \%$ petrol, $13 \%$ diesel).

The fuel flowed out of the bunker and downhill into the forest, rushing over the mossy boulder field between the pines and soaking into the soils beneath. $300 \mathrm{~m}$ from the bunker entrance, the fuel pooled in a hollow just next to the outer-most houses of Moheda, creating a lake of petrol. Fearing further fires in the area, the emergency response was to dose the area in water and cover it in soil.

Elsewhere, fire was used as the solution. The fuel had, through the sewages system, flooded onto a lake, covering the surface. In order to remove the contamination as quickly as possible, the surface of the lake was set alight, where it continued to burn for several days.

In total, around $45,000 \mathrm{~m}^{2}$ of mountainside was impacted, with free phase fuel and dissolved contamination being created in the fractured bedrock, glacial till, moraine and made ground across the site. After the immediate spill response, the impacted areas were left alone and the base was repaired and continued to operate.

In 2004 the site was shut down and remediation was deemed necessary due to vapours entering nearby properties and to allow redevelopment of the site. The Swedish Armed Forces had investigated the site and developed an outline remediation plan. RGS 90, a Swedish remediation contractor, was then employed to develop the remediation plan further and complete the remediation of the site.

The initial proposal provided by the problem holder to RGS 90 consisted of biosparging and in situ chemical oxidation (ISCO) using more than one million litres of hydrogen peroxide. RGS 90 had concerns regarding the inherent environmental and H\&S risks, as well as its validity due to the low permeability and heterogeneity of the site. RGS 90 approached Regenesis, an international remediation solutions provider, to assist in the development of an alternative strategy including the completion of pilot studies to prove the efficacy of the treatments and increase the accuracy and cost-effectiveness of the final doses used.

\section{PILOT STUDIES}

Two separate pilot studies were completed on the site in 2011; one in an area of higher contaminant concentrations where some Light Non-Aqueous Phase Liquid (LNAPL) was suspected to exist within the soil and fractures in the bedrock. An area of $10 \mathrm{~m}$ by $10 \mathrm{~m}$ was chosen and nine injection wells were installed within the area. Sampling of groundwater was carried out in 8 further wells, within and close to the injection area. Groundwater samples were taken before, during and after the injections. The area was treated with three application rounds of RegenOx. RegenOx is designed to chemically oxidise high concentrations of organic contaminants safely and without excess heat and pressure being produced.

The second pilot study was completed using ORC Advanced in order to trial the treatment of parts of the site impacted with dissolved phase petroleum hydrocarbon contamination only. 


\section{Linnaeus ECO-TECH '14}

Kalmar, Sweden, November 24-26, 2014

An area of $10 \mathrm{~m}$ by $10 \mathrm{~m}$ was chosen and direct push injection was carried out in 16 points within the area. Sampling of groundwater was carried out in 8 further wells within and close to the injection area before and after the injections. Groundwater samples were taken before and after the injection. The application of ORC Advanced created and sustained strongly aerobic conditions for approximately 12 months from a single injection, providing Enhanced Natural Attenuation (ENA) of the petroleum hydrocarbons within the groundwater.

In the RegenOx pilot trial area, a 50-95\% reduction in contaminant concentrations was seen due to in situ chemical oxidation (ISCO), with further degradation occurring through biological degradation of the partially oxidised residual contamination. In areas where adsorbed contamination or LNAPL was encountered, the analysis showed dissolution of the contaminants into the groundwater where they were then rapidly degraded, see Fig.1 for an example of this.

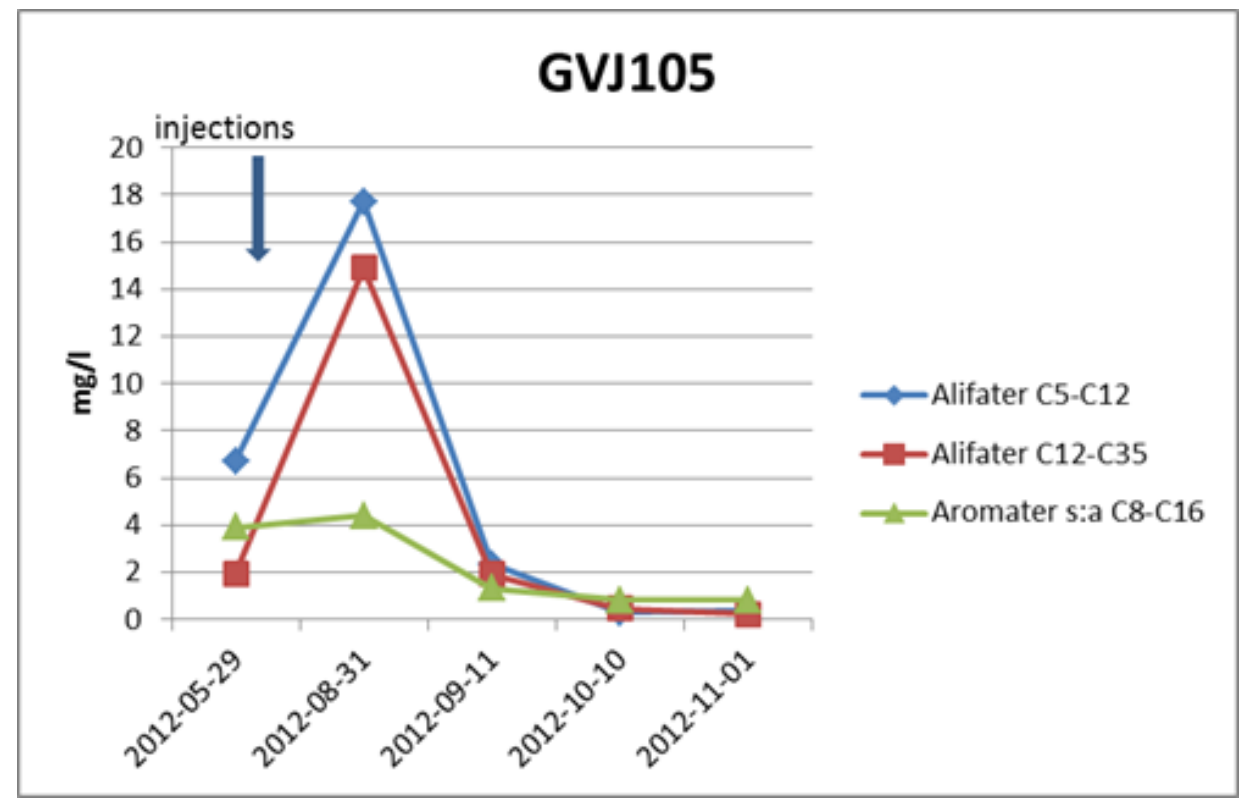

Figure 1: Results (point GVJ105) from RegenOx Pilot Area showing COC reaction to injection over time to non-detect

As can be seen in Fig.2, 95-99\% reductions in the dissolved phase contamination were achieved within a few months, with the technology still actively promoting the biological degradation of any residual contamination, beyond this time. 


\section{Linnaeus ECO-TECH '14}

Kalmar, Sweden, November 24-26, 2014

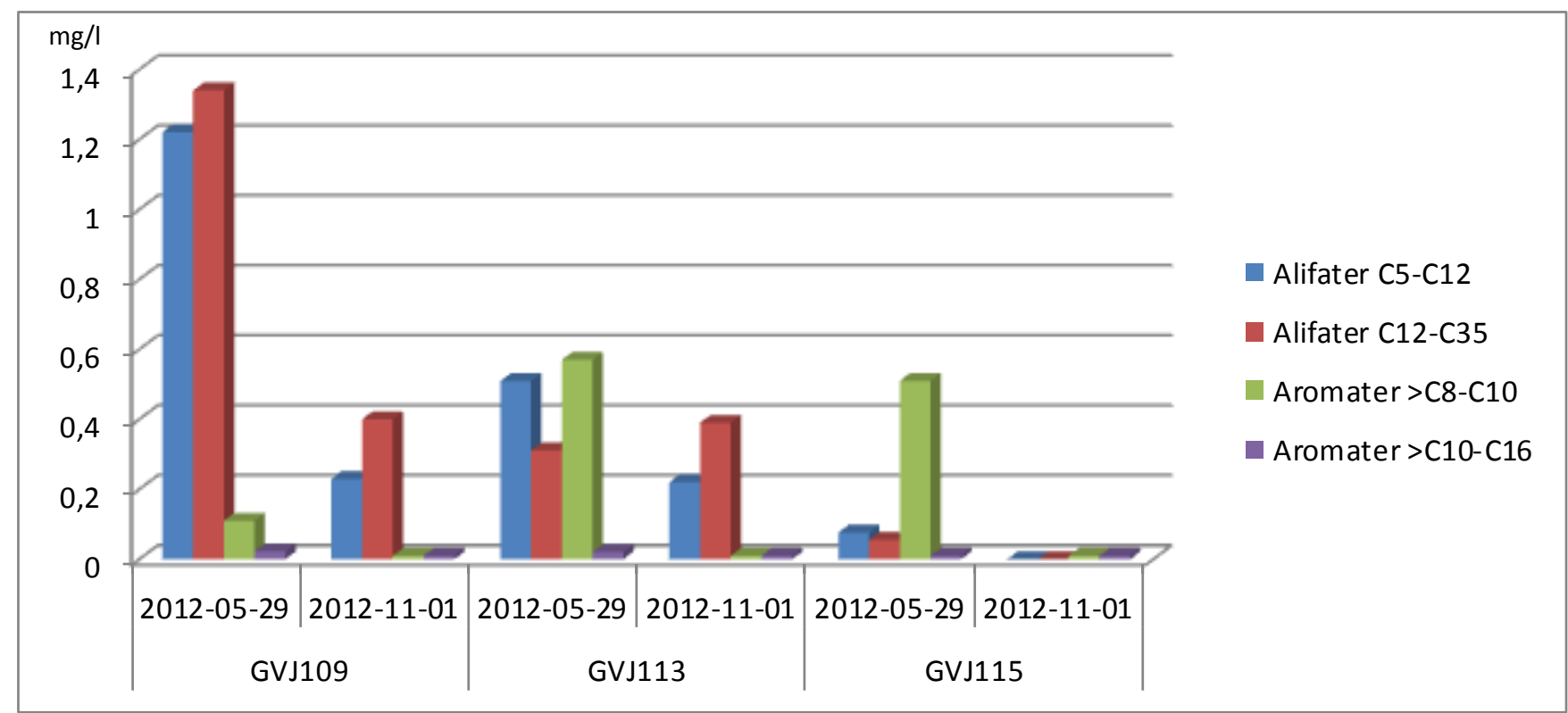

Figure 2: Results from ORC Advanced Area showing concentrations in 3 of the monitoring wells before and after treatment

The results from the pilot trials allowed RGS 90 to successfully prove that the remedial approach was valid and could be extrapolated to address the extensive TPH contamination across the site. The results assured the Swedish Armed Forces that this would be the most economical, technically viable, and effective integrated remedial solution at the site.

\section{FULL SCALE WORKS}

The decision was made to remediate the site in stages, with the smaller, upgradient areas being treated first (C and D-area). An extensive array of 30 boreholes were installed on a $20 \mathrm{~m}$ by $20 \mathrm{~m}$ grid, in order to further delineate the extent of the plume and improve the resolution of the contaminant concentrations and LNAPL distribution within it. The boreholes were then used as validation wells for the main works.

The data gathered from this work and the findings of the pilot study allowed Regenesis and RGS 90 to refine the treatment design. It was determined that areas showing $>10 \mathrm{mg} / \mathrm{L}$ total petroleum hydrocarbons (TPH) and/or the presence of LNAPL would be treated with three rounds of ISCO (provided by RegenOx), followed by ENA (using ORC Advanced). Areas with between 4 and $10 \mathrm{mg} / \mathrm{L}$ would be treated with intense ENA (a high dose of ORC Advanced) and areas with $<4 \mathrm{mg} / \mathrm{L}$ would receive a less intense ENA treatment (a lower dose of ORC Advanced). This approach would allow for the most cost-effective, applicable approach and would avoid wasted/misplaced product.

The first areas to be treated on the site required only dissolved phase contamination treatment using ENA. In December 2013, RGS 90 completed the injection of ORC Advanced into 257 points over an 8 week period. The application used direct push injection, see Fig 3, by which a hollow rod is driven into the ground and the requisite dose is injected into the contaminated part of the aquifer. Due to the geology a series of aliquots across the target thickness was not possible since insufficient sealing resulted in 'day lighting' of product back to the surface. 


\section{Linnaeus ECO-TECH '14}

Kalmar, Sweden, November 24-26, 2014

Therefore the ORC-Advanced was applied at a single depth and the distribution of oxygen across the target area was achieved through diffusion (the results of which were observed).

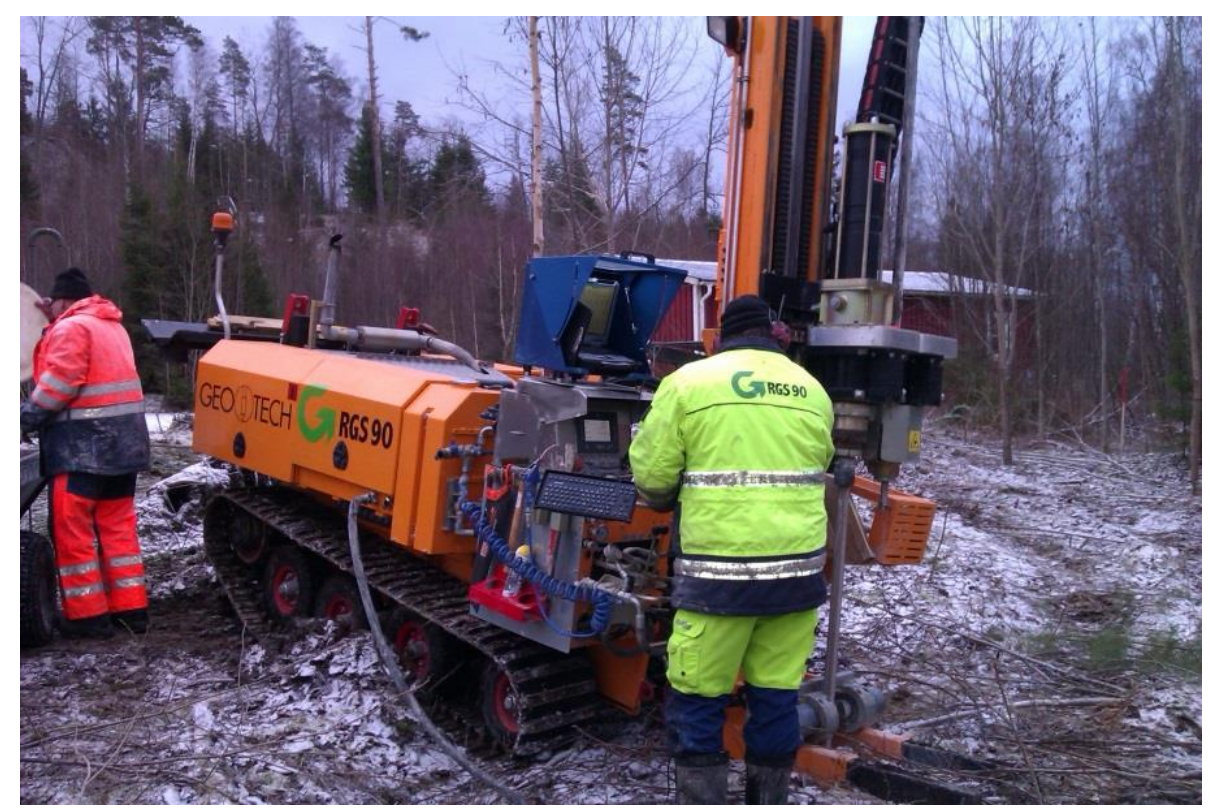

Figure 3: Direct push injection rig on site

\section{RESULTS AND DISCUSSION}

Validation sampling has been completed up to October 2014, see Fig. 4 and 5, which shows that TPH concentrations have dropped from a maximum of $12 \mathrm{mg} / \mathrm{L}$ to non-detect in most cases. Point GVB34 and C7 show a different pattern and higher levels of contamination has been detected during the last sampling in October 2014. C7 is situated in the outskirts of the treated area and might be suffering from influx of untreated contamination. GVB34 is situated in the center of the most contaminated area. The increasing levels of contamination might show that there is more adsorbed contamination which is dissolved into the groundwater by diffusion and when the groundwater level rises after quite a dry summer. 


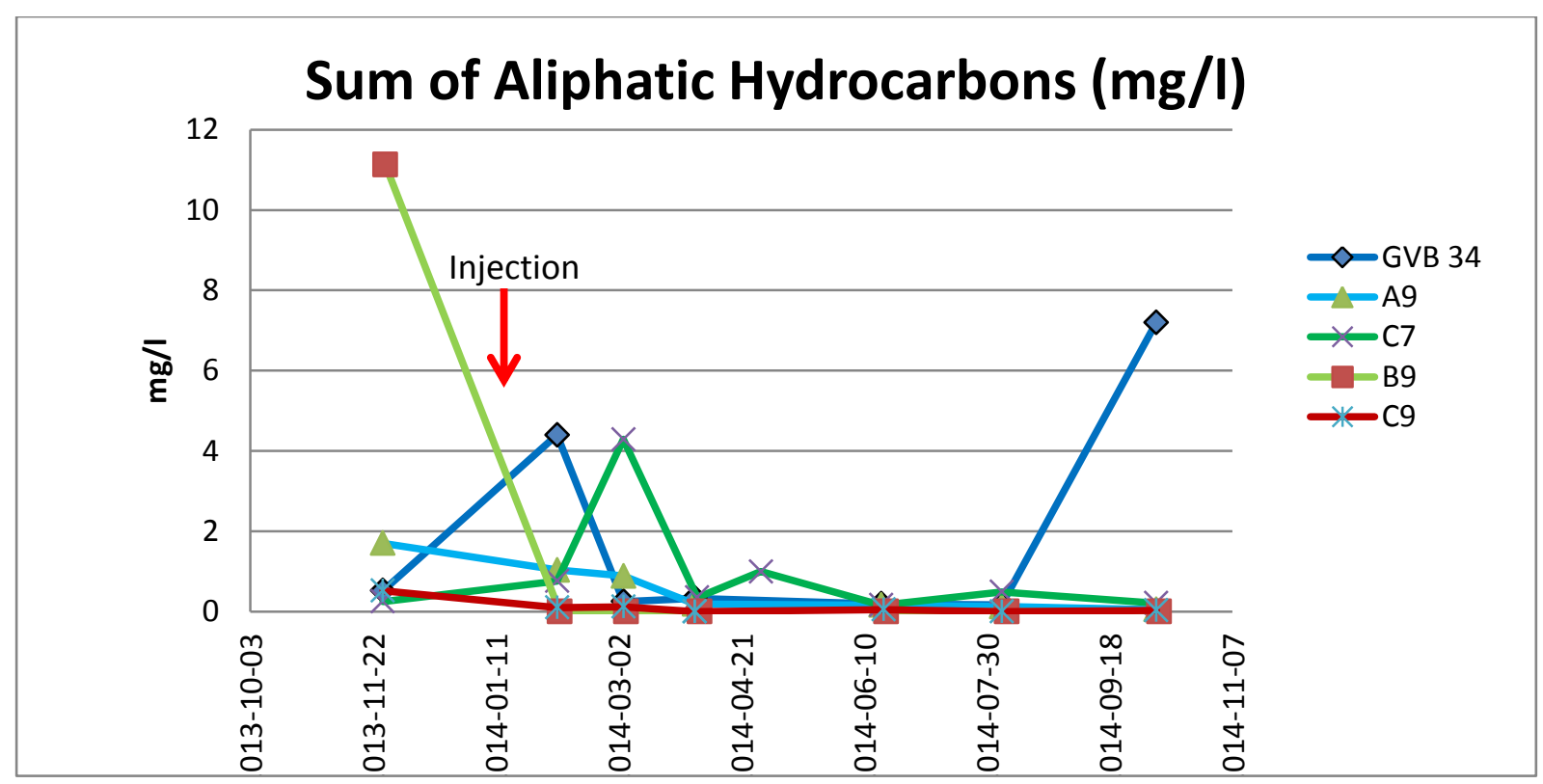

Figure 4: Phase 1; Concentration of Aliphatic Hydrocarbons over time.

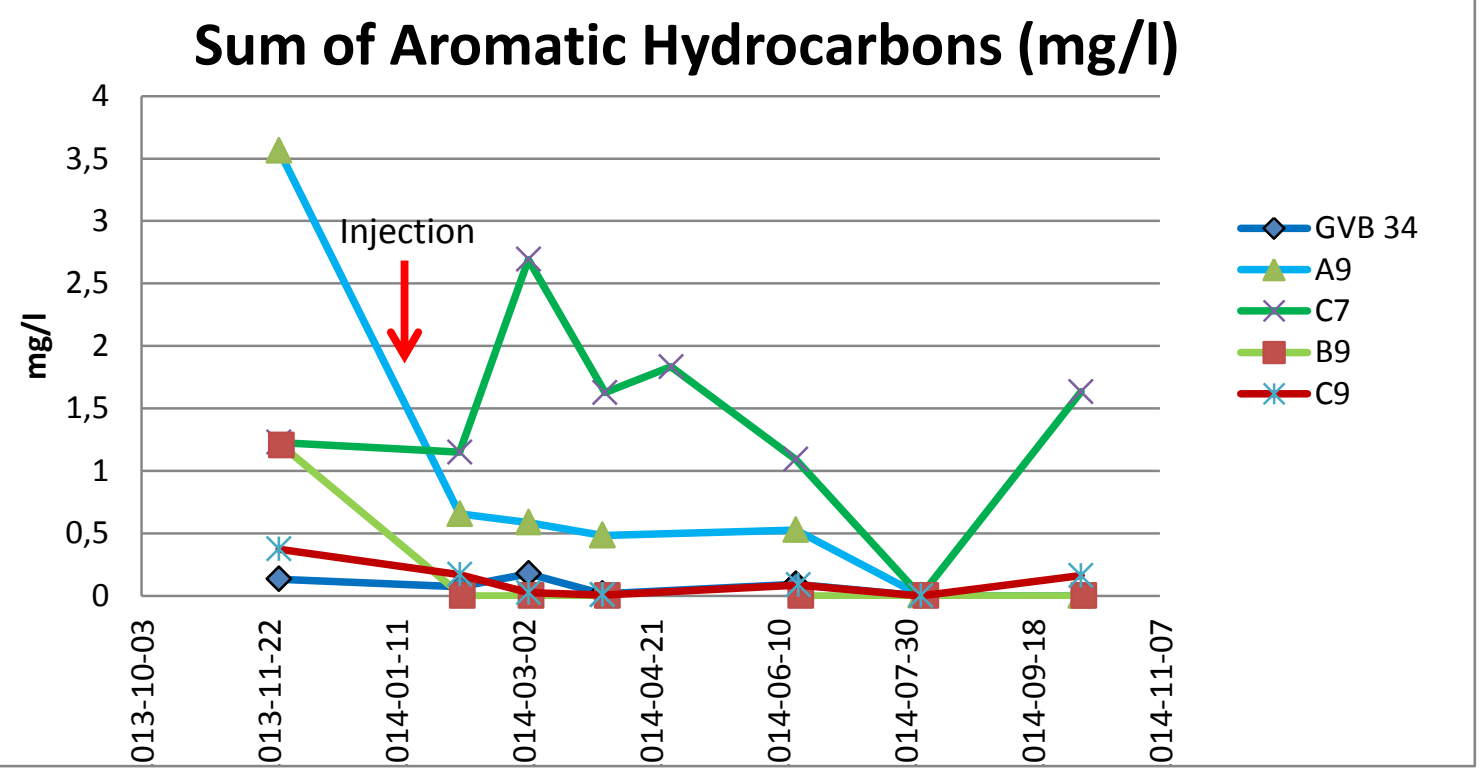

Figure 5: Phase 1; Concentration of Aromatic Hydrocarbons over time.

Validation sampling shows that the target levels have been achieved in all of the boreholes except two; less than one year after the injection. This proves that the selected remediation strategy seems to be successful at the site.

An extensive delineation and validation array has now been installed in the larger downgradient areas and RegenOx and ORC Advanced injection works are due to commence in autumn 2014 (Area B1-B3). An extensive array of 60 boreholes have been installed on a $20 \mathrm{~m}$ by $20 \mathrm{~m}$ grid, in order to further delineate the extent of the plume and improve the 
resolution of the contaminant concentrations and LNAPL distribution within it. The boreholes are then used as validation wells for the main works.

During delineation of Area B1-B3 a larger area of free phase product was detected. Also high levels of adsorbed contamination was detected. Due to this RGS 90 has proposed to use multiphase extraction, in addition to RegenOx and ORC Advanced, since this is most cost effective when removing higher levels of contamination.

\section{CONCLUSION}

This project is an excellent example of the value of a step-by-step approach to remediation; the initial concept was open to discussion and revision, which resulted in further site investigation and pilot studies to be undertaken. These then informed the full scale remediation design, resulting in the most accurate and cost effect treatment of the site. The project demonstrates the ability of integrated in situ techniques to meet the challenges of variable concentrations, free product, a heterogenetic formation and difficult terrain. This site shows that in situ remediation is capable of providing solutions to difficult, large scale and complicated problems, which would otherwise have relied on more expensive and disruptive traditional remediation methods. It is perhaps also fitting that a problem that started deep within the ground, should also be resolved beneath the soils of this quiet Swedish mountainside. 